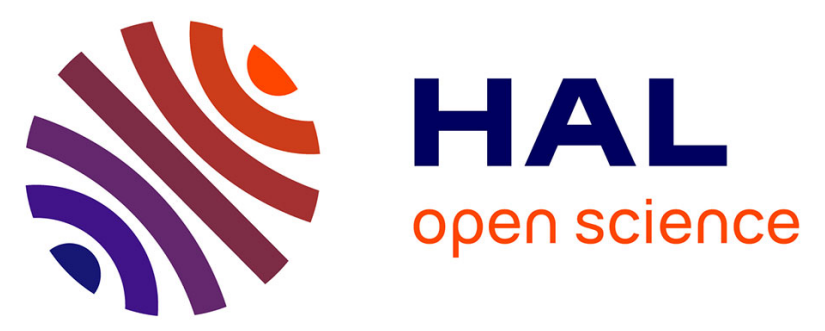

\title{
Understated Cognitive Impairment Assessed with the Clock-Drawing Test in Community-Dwelling Individuals Aged $\geq 50$ Years
}

Claire Leissing-Desprez, Emilie Thomas, Lauriane Segaux, Amaury Broussier, Nadia Oubaya, Nathalie Marie-Nelly, Marie Laurent, Laurent Cleret de Langavant, Isabelle Fromentin, Jean-Philippe David, et al.

\section{To cite this version:}

Claire Leissing-Desprez, Emilie Thomas, Lauriane Segaux, Amaury Broussier, Nadia Oubaya, et al.. Understated Cognitive Impairment Assessed with the Clock-Drawing Test in Community-Dwelling Individuals Aged $\geq 50$ Years. Journal of the American Medical Directors Association, 2020, 21 (11), pp.1658-1664. 10.1016/j.jamda.2020.03.016 . hal-03237386

\section{HAL Id: hal-03237386 https://hal.science/hal-03237386}

Submitted on 31 May 2021

HAL is a multi-disciplinary open access archive for the deposit and dissemination of scientific research documents, whether they are published or not. The documents may come from teaching and research institutions in France or abroad, or from public or private research centers.
L'archive ouverte pluridisciplinaire $\mathbf{H A L}$, est destinée au dépôt et à la diffusion de documents scientifiques de niveau recherche, publiés ou non, émanant des établissements d'enseignement et de recherche français ou étrangers, des laboratoires publics ou privés. 


\section{Understated Cognitive Impairment Assessed with the Clock-Drawing Test in Community-Dwelling Individuals Aged $\geq \mathbf{5 0}$}

Claire Leissing-Desprez MSca,b, Emilie Thomas MDb, Lauriane Segaux MSca,c, Amaury Broussier MDa,b, Nadia Oubaya MD, PhDa,d, Nathalie Marie-Nelly MDb, Marie Laurent MD, PhDa,b, Laurent Cleret de Langavant MD, PhDe,f, Isabelle Fromentin MD, MScb, JeanPhilippe David MD, PhDa,b*, Sylvie Bastuji-Garin MD, PhDa,c,d*

a Université Paris Est Créteil (UPEC), IMRB, CEpiA EA 7376 (Clinical Epidemiology and Ageing Unit), Créteil, France

b Assistance Publique Hôpitaux de Paris (AP-HP), Hôpitaux Henri-Mondor, Department of Geriatric Medicine, Créteil, France

c AP-HP, Hôpitaux Henri-Mondor, Clinical Research Unit (URC Mondor), Créteil, France

d AP-HP, Hôpitaux Henri-Mondor, Department of Public Health, Créteil, France

e AP-HP, Hôpitaux Henri-Mondor, Department of Neurology, Créteil, France

f INSERM U955 E01, IMRB \& ENS-DEC, PSL Research University (NeuroPsychologie Interventionnelle), Créteil \& Paris, France

* These authors contributed equally to the study

Address correspondence to: Claire Leissing-Desprez-Hôpital Emile Roux - Bât. Cruveilhier 1er étage - 1 Avenue de Verdun - BP60010-94456 Limeil-Brévannes cedex France

Tel.: +33-149-813-706; Fax: +33-149-813-697

E-mail: claire.leissing@aphp.fr

Running title: Cognitive Impairment in Middle-Aged Individuals 
Key words: Understated cognitive impairment, Clock-Drawing Test, screening, middleaged, elderly

Funding: This research did not receive any funding from agencies in the public, commercial, or not-for-profit sectors.

Word count: abstract, 298; main text, 2993

Tables: 2

Figure: 1

References: 47

Brief summary - Understated cognitive impairment is frequent (23.6\%) among communitydwelling individuals aged $\geq 50$, and is associated with factors known to be linked to a higher risk of cognitive decline and dementia

Acknowledgements - The authors thank David Fraser (Biotech Communication SARL, Ploudalmézeau, France) for editorial assistance. 


\section{ABSTRACT (298 words)}

1 Objectives: To estimate the prevalence of understated cognitive impairment by administering

2 the Clock-Drawing Test (CDT) to community-dwelling individuals aged $\geq 50$, and to

3 investigate the associated clinical phenotype.

4 Design: A cross-sectional analysis of baseline data on community-dwelling individuals

5 assessed at an outpatient clinic in the Paris region of France.

6 Setting and Participants: Participants aged $\geq 50(\mathrm{n}=488$, median age: 62.1$)$ prospectively

7 included in the SUCCEED survey between 2010 and 2014.

8 Methods: A multidimensional geriatric assessment, including cognition (7-point CDT,

9 MMSE, the 5-word screening test (5-WT), and the Frontal Assessment Battery (FAB)), gait

10 speed in dual tasks, mood (the Geriatric Depression Scale (GDS)), balance, physical

11 functions (gait speed and handgrip strength), nutrition, bone density, and comorbidities;

12 major cardiovascular risk factors, and Scheltens and Fazekas scores on brain MRI. Baseline

13 characteristics were analyzed as a function of the CDT score ( $<7$ versus 7$)$, using age-

14 adjusted logistic models.

15 Results: The prevalence of impairment in the CDT was $23.6 \%$ - higher than the values for 16 the MMSE (12.7\%), 5-WT (2.3\%) and FAB (16.6\%). In age-adjusted analyses, a lower

17 educational level (odds ratio $[95 \%$ confidence interval] $=0.72[0.58-0.89])$, diabetes $(2.57$

18 [1.14-5.79]), metabolic syndrome (1.93 [1.05-3.56]), lower gait speed in the cognitive dual 19 task (1.27 [1.05-1.53]), a poorer GDS score (1.86 [1.04-3.32]), a poorer MMSE score (2.56 20 [1.35-4.88]), a poorer FAB score (1.79 [1.01-3.16]), impaired episodic memory in the 5-WT 21 (4.11 [1.12-15.02]), and a higher Scheltens score $(P=.001)$ were significantly associated with 22 CDT impairment.

23 Conclusions and Implications: Understated cognitive impairment is common among young 24 seniors and is associated with factors known to be linked to a higher risk of cognitive decline 
25 and dementia. These findings suggest that the CDT may be of value for identifying high-risk 26 individuals who may then benefit from targeted multidomain prevention actions (diet, 27 exercise, cognitive training and vascular risk factor management). 


\section{Keywords}

Understated cognitive impairment, Clock-Drawing Test, screening, middle-aged, elderly 


\section{Introduction}

2

3 Cognitive decline is a common feature of ageing and is associated with an elevated

4 risk of dementia and disability. ${ }^{1}$ A transitional state between intact cognitive functioning and

5 clinical dementia has been described as mild cognitive impairment (MCI), defined as (i) the

6 reporting of cognitive complaints and objective cognitive impairment in one or more

7 cognitive domains and (ii) the preservation of functional abilities. ${ }^{2}$ However, recent results

8 from the SHARE study suggest that even subtle, understated cognitive impairment (defined

9 as impairment in one cognitive test score in an individual without cognitive complaints) is

10 predictive of an increased risk of adverse health outcomes and impaired functional capacity

11 in individuals aged $\geq 50 .{ }^{3}$ However, there are few published data on the prevalence of

12 understated cognitive impairment. In a subgroup analysis of the SUCCEED survey, we found

13 that $34 \%$ of asymptomatic individuals (free of dementia or cognitive complaints) aged $\geq 50$

14 had understated cognitive impairment, as assessed by poor performance in the Clock-

15 Drawing Test (CDT). ${ }^{4}$

16 The CDT has become one of the most commonly used cognitive screening 17 instruments. The test involves a diverse range of high-level cognitive abilities, such as 18 executive control, visuospatial and visuoconstructive functions, semantic memory, and 19 language skills. Impairments in these abilities may not be readily detected by other 20 commonly used cognitive screening tests, such as the Mini-Mental State Examination 21 (MMSE). ${ }^{5}$ Impairments in these cognitive abilities reflect possible frontal and 22 temporoparietal disturbances. The CDT has robust psychometric properties, including speed 23 of administration, easy scoring, patient acceptability, test-retest reliability, inter-rater 24 reliability, and high levels of sensitivity and specificity for identifying cognitive decline. ${ }^{6}$ The 25 literature data suggest that use of the CDT can readily detect early cognitive impairment in 
26 elderly people. ${ }^{5}$ Therefore, we hypothesized that an impairment in the CDT might be a useful

27 indicator of understated cognitive impairment (before the appearance of the first clinical

28 symptoms) in asymptomatic, community-dwelling, young seniors.

Although older age is the strongest risk factor for cognitive impairment, 30 cardiovascular risk factors and psychosocial risk factors (e.g. educational level and isolation)

31 have been also highlighted - suggesting that cognitive decline can be prevented (at least in 32 part) by targeting modifiable risk factors. ${ }^{1}$ With regard to the CDT, the literature data 33 evidence poorer performance among elderly patients with diabetes ${ }^{7,8}$ or with hypertension. ${ }^{9}$ Poor performance in the CDT is also reportedly associated with physical frailty in 35 asymptomatic adults aged $\geq 50^{10}$ and in older community-dwellers. ${ }^{11,12}$ The frailty 36 components most often associated with CDT impairment among elderly community-dwellers 37 were slow gait, low muscle strength, and decreased physical performance. ${ }^{11,13,14}$ Associations 38 between poor performance in the CDT on one hand and slow gait and low muscle strength on 39 the other have been also observed among younger community-dwellers. ${ }^{10}$ Furthermore, poor 40 CDT performance is reported associated with an increased risk of falls and fall-related 41 injuries $^{15}$ and with all-cause mortality. ${ }^{16}$ However, these studies generally included 42 individuals aged 65 and over, and so the prevalence of impaired performance in the CDT 43 among young seniors has not previously been reported. The Lancet Neurology Commission ${ }^{1}$ 44 pointed out that observational studies in community-dwellers are needed to monitor the 45 distribution of risk factors in different age groups. Few such studies have been performed in 46 middle-aged adults and younger elderly adults.

47 The objectives of the present study were therefore to estimate the prevalence of 48 understated_cognitive impairment (as assessed by the CDT) in a cohort of asymptomatic 49 community-dwelling individuals aged 50 years and over, and to investigate the associated 50 clinical phenotype. This knowledge might enable the earlier diagnosis of high-risk 
51 individuals, and then better management of their chronic comorbidities and/or frailty

52 symptoms. $^{17}$

53

54 Methods

55

56 Study population

57

58 We analyzed baseline data from the SUCCEED survey ${ }^{18}$ of community-dwellers aged

$59 \geq 50$, free of dementia and cognitive complaints, and_consecutively assessed at an outpatient

60 clinic in a 3000-bed university hospital in the greater Paris area of France. Individuals

61 underwent a multidimensional geriatric assessment (including evaluations of cognition,

62 mood, balance, mobility, muscle strength, nutrition, comorbidities, and bone density) and

63 brain MRI. For this cross-sectional analysis (SUCCEED-03), we included individuals

64 recruited between 2010 and 2014 and for whom CDT and MRI data were available (Figure

65 1). The study was approved by an institutional review board (CPP Ile-de-France X, Paris,

66 France, \# 96-2019).

67

68 Assessment

69

70 The data were collected prospectively using a standardized questionnaire.

71 Performance tests were conducted by trained nurses, and a standardized clinical assessment

72 was performed by a geriatrician (Table 1). Comorbidities were recorded, together with the

73 main cardiovascular risk factors: male gender, age >60 (in females), hypertension, smoking

74 (current or in the previous 3 years), LDL-cholesterol $>1.6 \mathrm{~g} / \mathrm{L}$, diabetes, dyslipidemia, one or

75 more first degree relatives having had a stroke before 45 years of age, sudden death, or 
76 myocardial infarction before the age of 55 (for men) or 65 (for women). Hypertension was

77 defined as a mean systolic blood pressure $\geq 140 \mathrm{mmHg}$, a mean diastolic blood pressure $\geq 90$

$78 \mathrm{mmHg}$, or ongoing antihypertensive treatment. The body mass index was calculated as 79 weight $(\mathrm{kg}) /$ height $^{2}\left(\mathrm{~m}^{2}\right)$. The Mini Nutritional Assessment Short-Form ${ }^{19}$ score was recorded 80 (risk of malnutrition: <12/14, i.e. $<12$ out of 14) along with unintentional weight loss over the 81 previous year. Waist circumference values $\geq 102 \mathrm{~cm}$ (for men) or $\geq 88$ (for women) were 82 considered to be abnormal. Metabolic syndrome (MetS) was defined as the combination of 83 three or more of the following conditions: hypertension, abnormal waist circumference, 84 fasting blood glucose $\geq 110 \mathrm{mg} / \mathrm{dL}$, triglycerides $\geq 150 \mathrm{mg} / \mathrm{dL}$, and HDL cholesterol <40 $85 \mathrm{mg} / \mathrm{dL}$ (for men) or $<50$ (for women). Mobility was assessed via a daily pedometer count 86 over a week (sedentary: $<7500$ steps/day) ${ }^{20}$ and gait speed over 10 meters (slowness: $<1$ $87 \mathrm{~m} / \mathrm{s}){ }^{21}$ Muscle strength was estimated by the dynamometer-measured peak dominant-hand 88 grip strength (JAMAR®, Sammons Preston, Bolingbrook, IL, USA), and the completion time 89 in a five-time sit-to-stand test (> $11.19 \mathrm{~s}) .{ }^{22}$ Weakness was defined as grip strength (kg) 90 stratified by gender and body mass index. ${ }^{23}$ Appendicular skeletal muscle mass was estimated 91 using dual energy X-ray absorptiometry (GE Healthcare, Lunar, Prodigy) and then used to 92 compute the appendicular lean mass index (low muscle mass: $<7.23 \mathrm{~kg} / \mathrm{m}^{2}$ (for men) or $<5.67$ 93 (for women)). ${ }^{24}$ Sarcopenia was defined as a combination of low muscle mass and low 94 muscle strength $\left(<30 \mathrm{~kg}\right.$ in men and $<20 \mathrm{~kg}$ in women) or slowness. ${ }^{24}$ Osteopenia and 95 osteoporosis were defined according to the bone mineral density T-score (osteopenia: 96 between -2.5 and -1 ; osteoporosis: $\leq-2.5$ ). Ten-meter walking test times during concurrent 97 tasks were also recorded. The one-leg standing test $(<5 s)^{25}$ and sternal push test were used to 98 assess balance. Lastly, the Geriatric Depression Scale (GDS) was used to explore mood (risk 99 of depression: $\geq 11 / 30$, or $\geq 5 / 15)$. ${ }^{26}$ Non-accidental falls in the previous year were also 100 recorded. 
102 last year), weakness, exhaustion (a self-reported feeling of generalized weakness over the last 103 year), slowness, and a low level of activity (<7500 steps per day and no regular physical 104 activity); ${ }^{23}$ the number of positive items defined the individuals as frail ( $\left.\geq 3\right)$, pre-frail (1-2) or 105 robust (none).

107 Evaluation of cognitive functions

All participants underwent a face-to-face neuropsychological assessment with a 110 trained geriatrician. The 7-point CDT (developed as part of the 7-Minute Screen battery) ${ }^{27}$ 111 was used to assess executive and visuospatial functions. This test is commonly used in 112 routine practice by geriatricians, and so was chosen because of its easy administration and 113 scoring. The patient was instructed to draw numbers and set the hands to a specific time on a 114 pre-drawn circle. The instruction was: "This circle represents a clock; place all the numbers 115 in the right place and place the hands at twenty minutes to four". The instruction could be 116 repeated during the test, as required. The CDT was scored as follows, with 1 point for each of 117 the 7 items: all the numbers draw, all the numbers in the right place, the sequence 1 to 12 118 intact, two hands present, the minute hand longer than the hour hand, the hour hand between 1193 and 4 o'clock, and the minute hand pointing to 8 . A CDT score $<7$ was taken as the cut-off 120 for impaired performance.

121 Overall cognitive performance was examined by the MMSE score adjusted for age 122 and years of schooling. ${ }^{28}$ The five-word screening test (5-WT) was used to assess episodic 123 memory $(<10 / 10),{ }^{29}$ and the Frontal Assessment Battery (FAB) was used to assess frontal 124 lobe functions $(<16 / 18){ }^{30}$ 
129 center were reviewed by two geriatricians with experience of neuroimaging interpretation. 130 The severity of white matter lesions (WMLs) was rated using a revised version of the 131 Fazekas scale (0, no WMLs; 1, punctate WMLs; 2, early confluent WMLs; 3, confluent

132 WMLs) ${ }^{31}$. The Scheltens score (from 0, no atrophy, to 4, severe atrophy) ${ }^{32}$ was used to assess 133 hippocampal atrophy.

135 Outcome measure

The primary outcome measure was the CDT score; a score $<7$ was denoted as 138 understated cognitive impairment.

140 Statistical analysis

142 Quantitative and qualitative variables were respectively described as the median 143 [interquartile range] and the number (\%). Continuous variables with a skewed distribution 144 were log-transformed prior to logistic regression analyses; their odds ratio (ORs) and 95\% 145 confidence interval (CIs) are given for one standard deviation (SD) of the log-transformed 146 value.

147 We compared participants with CDT results <7 vs. =7 using a Mann-Whitney, chi148 squared or Fisher's test, as appropriate. Odds Ratios [95\%CIs] were estimated using 149 asymptotic or exact logistic regression analyses for variables that yielded $P$ values $\leq .15$. Age150 adjusted ORs were also estimated. Analyses of cognitive test performances were 
systematically adjusted for GDS results and educational level. When over 5\% of the values

152 were missing, we estimated the ORs by applying a multiple-multivariate-imputations-by-

153 chained-equations procedure with the missing-at-random assumption. ${ }^{33}$ The threshold for 154 statistical significance was set to $P \leq .05$, and $P$ values between .05 and .10 were denoted as 155 indicating a trend. Analyses were performed using STATA, version 14.1 (StataCorp, College 156 Station, TX, US).

158 Results

A total of 488 participants were included in the analysis; the median (range) age was

16162.1 (50-87), 20.9\% had obtained a university degree, and the most prevalent cardiovascular 162 risk factors were dyslipidemia (in 34\% of the participants) and hypertension (30.7\%) (Table 163 1). About $68 \%$ of the participants were pre-frail and $5.5 \%$ were frail, according to the 164 physical frailty phenotype. Almost a quarter of the participants $(n=115)$ had a CDT score <7, 165 yielding a prevalence of $23.6 \%$ [95\% CI: 19.8-27.3\%]. About $15 \%$ of the participants had an 166 impaired MMSE or FAB score but very few (2.3\%) had abnormal 5-WT.

167 Individuals with an impaired CDT score were significantly older, were more likely to 168 smoke, to be obese, or to have diabetes or MetS, had more cardiovascular risk factors, and a 169 significantly slower gait speed in the single and dual tasks, relative to individuals with a 170 normal CDT score (Table 2). A non-significant trend was observed for a lower educational 171 level and hypertension. Individuals with impaired CDT performance were more likely to 172 have depressive symptoms and performed less well in the MMSE, 5-WT and FAB. Lastly, 173 participants with an impaired CDT score had significantly higher Scheltens scores. We did 174 not observe significant associations between the CDT score on one hand and the physical 175 frailty phenotype, history of non-accidental falls, or Fazekas score on the other. 
$177(P=.034)$, lower gait speed in the cognitive dual task $(P=.012)$, and depressive symptoms

$178(P=.037)$ were still significantly associated with a CDT score $<7$. A non-significant trend was

179 observed for smoking and obesity. Poorer cognitive performance in the MMSE $(P=.004), 5$ -

180 WT $(P=.033)$ and FAB $(P=.046)$, and a higher Scheltens score $(P=.015)$ were also

181 significantly associated with a CDT score $<7$ after adjustment for age. A non-significant trend 182 was observed for the association between 5-WT performance and the Scheltens score $183(P=.058)$.

\section{Discussion}

In a population of asymptomatic middle-aged and elderly community-dwellers

188 (median age: 62), the prevalence of understated cognitive impairment was $23.6 \%$. In age-

189 adjusted analyses, the factors significantly associated with impaired CDT performance were a

190 lower educational level, diabetes, MetS, depressive symptoms, a lower gait speed in the

191 cognitive dual task, poorer performance in the MMSE, 5-WT, and FAB tests, and a higher

192 Scheltens score. In our study population, the CDT score was not associated with physical

193 frailty or the Fazekas score.

194 To the best of our knowledge, the present study is the first to have investigated the 195 prevalence of understated cognitive impairment (as assessed by the CDT) and the associated

196 clinical phenotype among asymptomatic community-dwellers aged 50 and over. The CDT 197 and the MMSE are good screening tests for impairments in overall cognition. ${ }^{6}$ Compared 198 with the MMSE, the CDT is better able to detect impairments in visuoconstructive and 199 executive abilities. ${ }^{5,6}$ Given that a decline of executive control in normal aging may be 200 predictive of a change in functional status, ${ }^{34}$ the detection of a mild impairment in executive 
201 function in relatively young seniors may be of value in preventing dementia or delaying its

202 onset through multidomain interventions and better overall management (e.g. diet, exercise,

203 cognitive training, and the treatment of vascular risk factors). ${ }^{35}$

204 The prevalence of impaired CDT performance in the present study was $23.6 \%$; this is

205 within the range from 20.1 to $32.2 \%$ reported for MCI in community-dwellers $\geq 65$ years. ${ }^{16}$

206 However, another study reported a rate of $60.6 \%$ for adults aged $\geq 65 .{ }^{11}$ The only study that

207 investigated community-dwellers aged $\geq 50$ reported mean CDT scores but not a prevalence

208 rate. ${ }^{10}$ As expected, we found that individuals with an impaired CDT score were significantly

209 older and had a lower educational level. ${ }^{6,36}$

210 In line with reports on older populations, individuals with an impaired CDT score

211 were more likely to have cardiovascular risk factors such as diabetes and MetS. ${ }^{7,8,37}$ In

212 contrast, other components of the MetS (hypertension, abdominal obesity, and dyslipidemia)

213 were not significantly associated with impaired CDT performance. However, it has been

214 reported that the association between MetS and decline in cognitive function (as assessed by

215 CDT) was not attributable to its individual altered components. ${ }^{37}$ Therefore, we can assume

216 that the negative effect of MetS on cognitive functions is greater than the cumulative effect of

217 its components. However, further studies are needed to better characterize the role of MetS in

218 age-related cognitive impairment.

219 In contrast to the literature data on elderly individuals, we did not observe an 220 association between impaired CDT performance and physical frailty or physical functions 221 impairment. This may be due in part to the low prevalence of frail subjects $(5.5 \%)$ in our 222 population of young seniors. Furthermore, it has been shown that a decline in executive 223 function predicts (and therefore precedes) the onset of physical frailty. ${ }^{38}$ However, we 224 observed a significant association between CDT impairment and the time needed to walk 10 225 meters in the cognitive dual task. This relationship suggests that (i) the cognitive dual task 
226 can tax various cognitive resources to varying degrees, and (ii) executive function is one of

227 the key determinants of dual-task ability. ${ }^{39}$ Lastly, walking and gait disturbances might also

228 be predictors of cognitive impairment and dementia. ${ }^{40}$

229 In line with the literature data, individuals with impaired CDT performance were 230 more likely to have depressive symptoms. ${ }^{41}$ After adjustment for factors known to affect 231 scores in cognitive tests (age, educational level, and depressive symptoms), impaired CDT 232 performance was still significantly associated with impairment in screening tests for global 233 cognitive alterations (MMSE), episodic memory performance (5-WT), and executive 234 functions (FAB); again, this agrees with the literature data. ${ }^{5,42}$ These findings support the 235 hypothesis whereby the CDT assesses a broad range of cognitive abilities and may probe the 236 integration of several cognitive domains required for task performance.

237 Regarding the MRI results, we did not observe an association between impaired CDT 238 performance and the Fazekas score. However, this type of association was expected because 239 according to the literature data, the presence of white matter hyperintensities is associated 240 with lower CDT scores. ${ }^{43}$ It may be that the low prevalence of severe WMLs in our study 241 population prevented us from observing an association. Conversely, we confirmed that 242 impaired CDT performance is associated with a higher Scheltens score, a hallmark of 243 hippocampal atrophy ${ }^{44}$ usually associated with poor episodic memory, especially in 244 Alzheimer's disease. ${ }^{45}$ Importantly, hippocampal atrophy is also associated with other 245 neurodegenerative disorders, such as hippocampal sclerosis, Lewy-related pathologies, and 246 argyrophilic grain disease. ${ }^{46}$ It is noteworthy that in our study, poor performance in the 5-WT 247 (an episodic memory test associated with impaired CDT performance here and in the 248 literature $^{6}$ ) was associated (albeit non-significantly; $P=.058$ ) with hippocampal atrophy. 249 However, the prevalence of impaired 5-WT performance in our population of young seniors 250 was only $2.3 \%$ - much less than the value of $23.6 \%$ for impaired CDT performance. Given 
251 that the CDT is a multidomain test (rather than an episodic memory test), we suggest that it

252 might be better than the 5-WT for screening for understated cognitive impairment associated

253 with hippocampal atrophy in relatively young populations.

254 The main strengths of our study were the prospective recruitment of participants, and

255 the use of validated measurement tools that comply with international guidelines. The CDT is

256 a validated instrument with solid psychometric properties for identifying cognitive decline.

257 Although there is a lack of a consensus on the most appropriate scoring system for CDT, our

258 application of the same scoring system to all participants in the SUCCEED survey precludes

259 differential bias. Furthermore, we routinely adjusted our analyses for potential confounders

260 such as age, educational level and depressive symptoms. Other potential limitations include

261 the single-center, cross-sectional design; this limits external validity and cannot provide

262 information on the temporal relationship between impaired CDT performance and other study

263 variables.

264

\section{Conclusions and implications}

Almost a quarter of asymptomatic middle-aged and elderly community-dwellers had 268 understated cognitive impairment (as assessed by the CDT). The clinical phenotype 269 associated with CDT impairment included cardiovascular risk factors, depressive symptoms, 270 a lower educational level, worse cognitive performance in dual tasks and in memory or 271 executive tasks, and a higher degree of hippocampal atrophy. These factors (some of which 272 are modifiable) are known to be related to a higher risk of cognitive decline and dementia. 273 Conversely, impaired CDT performance was not associated with physical frailty in this 274 population of young seniors. The CDT may be of value in detecting understated cognitive 
275 impairment in younger seniors, better managing their risk factors for dementia, and thus 276 preventing or at least delaying functional decline and dementia.

277

\section{Conflict of interest}

280 The authors disclose no conflicts of interest.

\section{References}

1. Winblad B, Amouyel P, Andrieu S, et al. Defeating Alzheimer's disease and other dementias: a priority for European science and society. Lancet Neurol 2016;15(5):455-532.

2. Petersen RC, Caracciolo B, Brayne $\mathrm{C}$ et al. Mild cognitive impairment: a concept in evolution. J Intern Med. 2014 Mar;275(3):214-28.

3. Sterniczuk R, Theou O, Rusak B, Rockwood K. Cognitive Test Performance in Relation to Health and Function in 12 European Countries: The SHARE Study. Can Geriatr J 2015;18(3):144-151.

4. David JP, Ferrat E, Parisot J, et al. White Matter Lesions: Prevalence and Clinical Phenotype in Asymptomatic Individuals Aged $\geq 50$ Years. Dement Geriatr Cogn Disord 2016;42(3-4):159-168.

5. Shulman KI. Clock-drawing: is it the ideal cognitive screening test? Int J Geriatr Psychiatry 2000;15(6):548-561.

6. Pinto E, Peters R. Literature Review of the Clock Drawing Test as a Tool for Cognitive Screening. Dement Geriatr Cogn Disord 2009;27(3):201-213. 
7. Wennberg AMV, Hagen CE, Gottesman RF, et al. Longitudinal association between diabetes and cognitive decline: The National Health and Aging Trends Study. Arch Gerontol Geriatr 2017;72:39-44.

8. Herghelegiu AM, Nacu RM, Prada GI. Metabolic parameters and cognitive function in a cohort of older diabetic patients. Aging Clin Exp Res 2016;28(6):1105-1112.

9. Spinelli C, De Caro MF, Schirosi G, et al. Impaired cognitive executive dysfunction in adult treated hypertensives with a confirmed diagnosis of poorly controlled blood pressure. Int J Med Sci 2014;11(8):771-778.

10. Wu YH, Liu LK, Chen WT, et al. Cognitive Function in Individuals With Physical Frailty but Without Dementia or Cognitive Complaints: Results From the I-Lan Longitudinal Aging Study. J Am Med Dir Assoc 2015;16(10):899.e9-16.

11. Yassuda MS, Lopes A, Cachioni M, et al. Frailty criteria and cognitive performance are related: data from the FIBRA study in Ermelino Matarazzo, São Paulo, Brazil. J Nutr Health Aging 2012;16(1):55-61.

12. Rosado-Artalejo C, Carnicero JA, Losa-Reyna J, et al. Cognitive Performance across 3 Frailty Phenotypes: Toledo Study for Healthy Aging. J Am Med Dir Assoc 2017;18(9):785-790.

13. Beauchet O, Allali G, Montero-Odasso M, et al. Motor Phenotype of Decline in Cognitive Performance among Community-Dwellers without Dementia: Population-Based Study and Meta-Analysis. PLoS One 2014;9(6):e99318.

14. Viscogliosi G, Bernardo MG di, Ettorre E, Chiriac IM. Handgrip strength predicts longitudinal changes in clock drawing test performance. An observational study in a sample of older non-demented adults. J Nutr Health Aging 2017;21(5):593-596. 
15. Kearney FC, Harwood RH, Gladman JRF, et al. The Relationship between Executive Function and Falls and Gait Abnormalities in Older Adults: A Systematic Review. Dement Geriatr Cogn Disord 2013;36(1-2):20-35.

16. Forti P, Maioli F, Lega MV, et al. Combination of the Clock Drawing Test with the Physical Phenotype of Frailty for the Prediction of Mortality and Other Adverse Outcomes in Older Community Dwellers without Dementia. Gerontology 2014;60(3):204-211.

17. Rakesh G, Szabo ST, Alexopoulos GS, Zannas AS. Strategies for dementia prevention: latest evidence and implications. Ther Adv Chronic Dis 2017;8(8-9):121-136.

18. Segaux L, Oubaya N, Broussier A, et al. Identification of five frailty profiles in community-dwelling individuals aged 50-75: A latent class analysis of the SUCCEED survey data. Maturitas 2019;127:1-11.

19. Rubenstein LZ, Harker JO, Salvà A, et al. Screening for undernutrition in geriatric practice: developing the short-form mini-nutritional assessment (MNA-SF). J Gerontol A Biol Sci Med Sci 2001;56(6):M366-372.

20. Tudor-Locke C, Bassett DR. How many steps/day are enough? Preliminary pedometer indices for public health. Sports Med Auckl NZ 2004;34(1):1-8.

21. Cesari M, Kritchevsky SB, Penninx BWHJ, et al. Prognostic value of usual gait speed in well-functioning older people-results from the Health, Aging and Body Composition Study. J Am Geriatr Soc 2005;53(10):1675-1680.

22. Guralnik JM, Ferrucci L, Pieper CF, et al. Lower extremity function and subsequent disability: consistency across studies, predictive models, and value of gait speed alone compared with the short physical performance battery. J Gerontol A Biol Sci Med Sci 2000;55(4):M221-231.

23. Fried LP, Tangen CM, Walston J, et al. Frailty in older adults: evidence for a phenotype. J Gerontol A Biol Sci Med Sci 2001;56(3):M146-156. 
24. Cruz-Jentoft AJ, Baeyens JP, Bauer JM, et al. Sarcopenia: European consensus on definition and diagnosis: Report of the European Working Group on Sarcopenia in Older People. Age Ageing 2010;39(4):412-423.

25. Vellas BJ, Wayne SJ, Romero L, et al. One-leg balance is an important predictor of injurious falls in older persons. J Am Geriatr Soc 1997;45(6):735-738.

26. Dennis M, Kadri A, Coffey J. Depression in older people in the general hospital: a systematic review of screening instruments. Age Ageing 2012;41(2):148-154.

27. Solomon PR, Hirschoff A, Kelly B, et al. A 7 minute neurocognitive screening battery highly sensitive to alzheimer's disease. Arch Neurol 1998;55(3):349-355.

28. Crum RM, Anthony JC, Bassett SS, Folstein MF. Population-based norms for the MiniMental State Examination by age and educational level. JAMA 1993;269(18):2386-2391.

29. Mormont E, Jamart J, Robaye L. Validity of the five-word test for the evaluation of verbal episodic memory and dementia in a memory clinic setting. J Geriatr Psychiatry Neurol $2012 ; 25(2): 78-84$

30. Dubois B, Slachevsky A, Litvan I, Pillon B. The FAB: A frontal assessment battery at bedside. Neurology 2000;55(11):1621-1626.

31. Fazekas F, Chawluk JB, Alavi A, et al. MR signal abnormalities at $1.5 \mathrm{~T}$ in Alzheimer's dementia and normal aging. AJR Am J Roentgenol 1987;149(2):351-356

32. Scheltens P, Leys D, Barkhof F, et al. Atrophy of medial temporal lobes on MRI in "probable" Alzheimer's disease and normal ageing: diagnostic value and neuropsychological correlates. J Neurol Neurosurg Psychiatry 1992;55(10):967-72.

33. White IR, Royston P, Wood AM. Multiple imputation using chained equations: Issues and guidance for practice. Stat Med 2011;30(4):377-399. 
34. Royall DR, Lauterbach EC, Kaufer D, et al. The cognitive correlates of functional status: a review from the Committee on Research of the American Neuropsychiatric Association. $\mathbf{J}$ Neuropsychiatry Clin Neurosci 2007;19(3):249-265.

35. Ngandu T, Lehtisalo J, Solomon A, et al. A 2 year multidomain intervention of diet, exercise, cognitive training, and vascular risk monitoring versus control to prevent cognitive decline in at-risk elderly people (FINGER): a randomised controlled trial. The Lancet 2015;385(9984):2255-2263.

36. Hubbard EJ, Santini V, Blankevoort CG, et al. Clock Drawing Performance in Cognitively Normal Elderly. Arch Clin Neuropsychol Off J Natl Acad Neuropsychol 2008;23(3):295-327.

37. Viscogliosi G, Chiriac IM, Andreozzi P, Ettorre E. The Metabolic Syndrome Predicts Longitudinal Changes in Clock Drawing Test Performance in Older Nondemented Hypertensive Individuals. Am J Geriatr Psychiatry 2016;24(5):359-363.

38. Gross AL, Xue QL, Bandeen-Roche K, et al. Declines and Impairment in Executive Function Predict Onset of Physical Frailty. J Gerontol A Biol Sci Med Sci 2016;71(12):1624-1630.

39. Holtzer R, Wang C, Lipton R, Verghese J. The protective effects of executive functions and episodic memory on gait speed decline in aging defined in the context of cognitive reserve. J Am Geriatr Soc 2012;60(11):2093-2098.

40. Rosso AL, Verghese J, Metti AL, et al. Slowing gait and risk for cognitive impairment: The hippocampus as a shared neural substrate. Neurology 2017;89(4):336-342.

41. Kirby M, Denihan A, Bruce I, et al. The clock drawing test in primary care: sensitivity in dementia detection and specificity against normal and depressed elderly. Int $\mathbf{J}$ Geriatr Psychiatry 2001;16(10):935-940. 
42. Paula JJ de, Miranda DM de, Moraes EN de, Malloy-Diniz LF. Mapping the clockworks: what does the Clock Drawing Test assess in normal and pathological aging? Arq Neuropsiquiatr 2013;71(10):763-768.

43. Supasitthumrong T, Herrmann N, Tunvirachaisakul C, Shulman K. Clock drawing and neuroanatomical correlates: A systematic review. Int J Geriatr Psychiatry. 2019 Feb;34(2):223-232.

44. Hirjak D, Sambataro F, Remmele B, et al. The relevance of hippocampal subfield integrity and clock drawing test performance for the diagnosis of Alzheimer's disease and mild cognitive impairment. World J Biol Psychiatry Off J World Fed Soc Biol Psychiatry 2019;20(3):197-208.

45. Dubois B, Feldman HH, Jacova C, et al. Research criteria for the diagnosis of Alzheimer's disease: revising the NINCDS-ADRDA criteria. Lancet Neurol 2007;6(8):734-746.

46. Barkhof F, Polvikoski TM, van Straaten ECW, et al. The significance of medial temporal lobe atrophy: a postmortem MRI study in the very old. Neurology 2007;69(15):1521-1527. 
Table 1. Characteristics of the study population $(\mathrm{N}=488)$

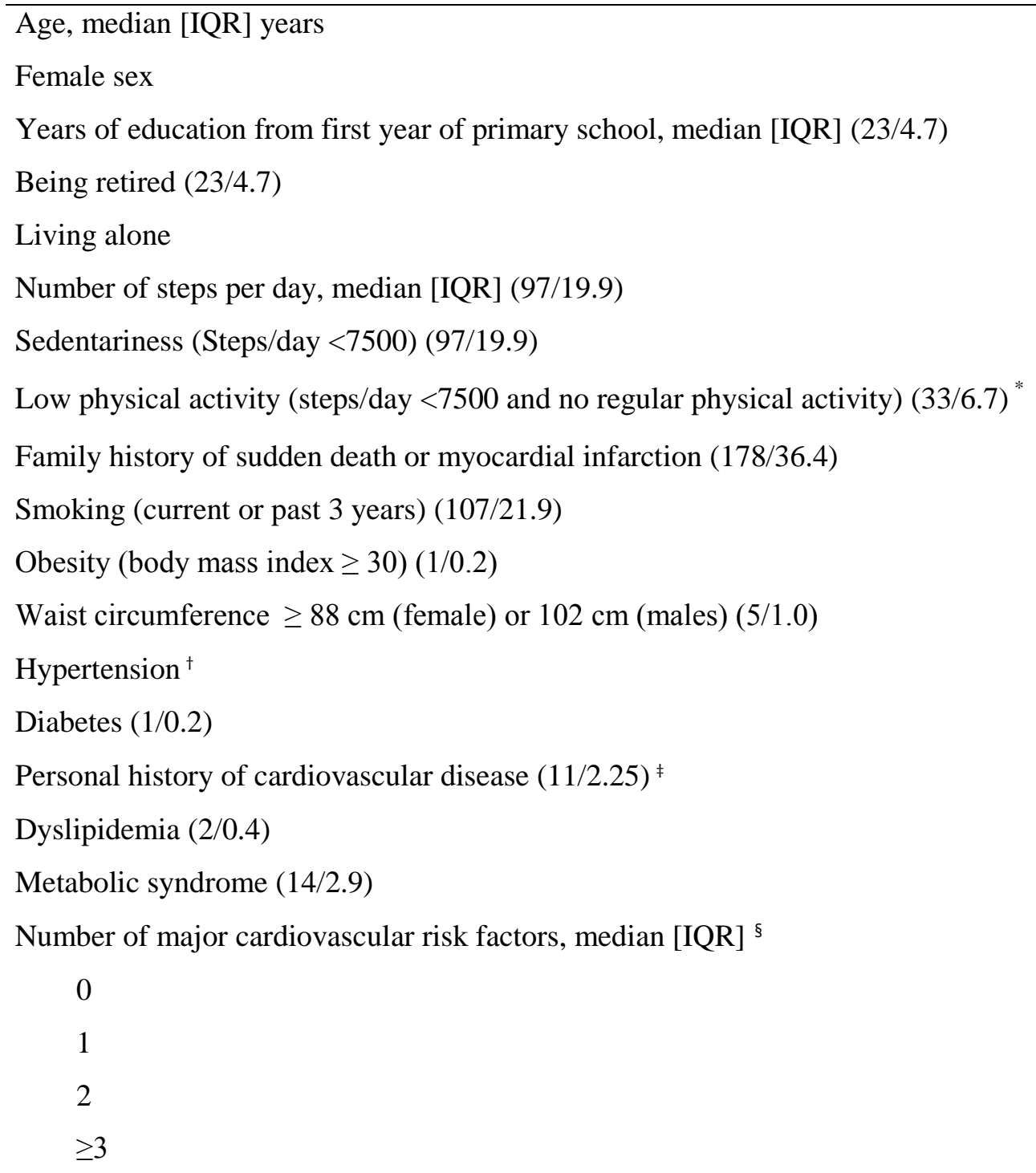

One or more non-accidental falls in the year (6/1.2)

$62.1[57.4-67.1]$

$328(67.2)$

12 [11-15]

260(53.7)

140 (28.7)

7405 [5154-10211]

$196(50.1)$

$194(41.9)$

$15(4.8)$

$31(8.1)$

$68(14.0)$

$232(48.0)$

$150(30.7)$

$27(5.5)$

$25(5.2)$

$165(34.0)$

$55(11.6)$

$1[1-2]$

$76(15.6)$

$179(36.7)$

$155(31.8)$

$78(16.0)$

$41(8.5)$

$25(5.2)$

$15(3.2)$

Unintentional weight loss $\geq 4.5 \mathrm{~kg}$ in the past year (32/6.5)

\section{Mobility and muscle strength}

Gait speed m/s, median [IQR]

$1.43[1.25-1.64]$

Slowness (gait speed $<1 \mathrm{~m} / \mathrm{s})(1 / 0.2)$

Ten-meter walking test times during a concurrent motor task, $\mathrm{s}$

Ten-meter walking test times during a concurrent cognitive task, $\mathrm{s}$

$7.7[6.8-9]$

$49(10.0)$

178 (36.6)

Weakness, grip strength $(\mathrm{kg})$ stratified by sex and body mass index

$50(10.5)$ 


\section{Balance}

One-leg standing test $(6 / 1.2)<5 \mathrm{~s}$

Failure to resist a sternal push (14/2.9)

\section{Bone mineral density (15/3.1)}

Normal (T-score > -1)

Osteopenia (T-score between -1 and -2.5)

Osteoporosis (T-score $<=-2.5$ )

Exhaustion (122/24.6)

Physical frailty phenotype (modified CHS criteria) $(6 / 1.2 \%) "$

Robust

Pre-frail

Frail

Depressive symptoms (GDS $\geq 11 / 30$ or $5 / 15)(63 / 12.9)$

\section{Cognition}

Clock drawing test $<7$

MMSE $\leq$ lower quartile according to age and education (23/4.7)

Five-word test score $<10$

Frontal Assessment Battery score < $16(1 / 0.2)$

\section{Brain MRI}

Scheltens score $(86 / 17.6)$

0

Fazekas score (118/24.2)

$0-1$

Variables are expressed as the $\mathrm{n}(\%)$, unless otherwise stated; (/) indicates the number and \% of missing values.

Abbreviations: IQR, interquartile range; MNA, Mini Nutritional Assessment; MMSE, Mini Mental State Examination; GDS, Geriatric Depression Scale; CHS, Cardiovascular Health Study; MRI, magnetic resonance imaging.

* Regular physical activity including walking, recreational sports and other physical activities.

${ }^{\dagger}$ Hypertension, defined as a systolic blood pressure $\geq 140 \mathrm{mmHg}$ or a diastolic blood pressure $\geq 90$ $\mathrm{mmHg}$ or ongoing treatment for hypertension. 
${ }^{\ddagger}$ History of cardiovascular disease, including stroke, transient ischemic attack, or coronary heart disease.

${ }^{\S}$ Major cardiovascular risk factors include: male sex, age >60 years (female), hypertension, smoking (current or past 3 years), dyslipidemia, diabetes, and first degree relative(s) with stroke before 45 years of age, sudden death, or myocardial infarction before 55 [men] or 65 (women) years of age.

I The modified CHS criteria were unintentional weight loss $\geq 4.5 \mathrm{~kg}$ in the year, self-reported exhaustion, poor grip strength, gait speed $<1 \mathrm{~m} / \mathrm{s}$ and low physical activity $(<7500$ steps/day and no regular physical activity). Individuals with $\geq 3$ criteria are considered to be frail, those with 1-2 criteria are considered to be pre-frail, and those with no criteria are considered to be robust. 
Table 2. Characteristics of the study participants as a function of the CDT score (univariate and age-adjusted analyses)

\begin{tabular}{|c|c|c|c|c|c|c|}
\hline & \multicolumn{2}{|c|}{ Clock-Drawing Test score } & \multicolumn{2}{|c|}{ Univariate analysis } & \multicolumn{2}{|c|}{ Age adjusted analysis } \\
\hline & $\begin{array}{c}7 \\
(\mathrm{~N}=373)\end{array}$ & $\begin{array}{c}<7 \\
(\mathrm{~N}=115)\end{array}$ & $P$ value ${ }^{*}$ & OR $[95 \% \mathbf{C I}]^{\dagger}$ & $\mathrm{OR}[95 \% \mathrm{CI}]^{\ddagger}$ & $P$ value \\
\hline Age, median [IQR] years & $61.4[56.6-66.0]$ & $63.9[59.3-70.0]$ & $<.001$ & $1.07[1.04-1.11]$ & & \\
\hline Female sex & $256(68.6)$ & $72(62.6)$ & .229 & & & \\
\hline $\begin{array}{l}\text { Years of full-time education from the first year of } \\
\text { primary school, median }[\mathrm{IQR}]^{\S}\end{array}$ & $12[11-15]$ & $12[11-15]$ & .058 & $0.70[0.56-0.86]$ & $0.72[0.58-0.89]$ & .003 \\
\hline Living alone & $104(27.9)$ & $36(31.3)$ & .478 & & & \\
\hline $\begin{array}{l}\text { Low physical activity (steps/day< } 7500 \text { and no regular } \\
\text { physical activity) }\end{array}$ & $145(41.7)$ & $48(44.4)$ & .61 & & & \\
\hline $\begin{array}{l}\text { First-degree relatives with a history of sudden death or } \\
\text { myocardial infarction }{ }^{\dagger \dagger}\end{array}$ & $14(6.0)$ & $1(1.3)$ & .274 & & & \\
\hline Personal history of cardiovascular disease ${ }^{\ddagger}$ & $16(4.4)$ & $9(8.2)$ & .115 & $1.95[0.84-4.56]$ & $1.30[0.53-3.18]$ & .559 \\
\hline Smoking (current or past 3 years) & $19(6.5)$ & $12(13.3)$ & .039 & $1.89[0.87-4.09]$ & $2.17[0.96-4.92]$ & .062 \\
\hline Obesity (body mass index $\geq 30$ ) & $45(12.1)$ & $23(20.0)$ & .034 & $1.82[1.04-3.16]$ & $1.65[0.94-2.92]$ & .083 \\
\hline $\begin{array}{l}\text { Waist circumference } \geq 88 \mathrm{~cm} \text { (female) or } 102 \mathrm{~cm} \\
\text { (males) }\end{array}$ & $172(46.7)$ & $60(52.2)$ & .309 & & & \\
\hline Hypertension $\S^{\S}$ & $107(28.7)$ & $43(37.4)$ & .077 & $1.48[0.96-2.30]$ & $1.19[0.75-1.88]$ & .46 \\
\hline Diabetes & $15(4.0)$ & $12(10.4)$ & .011 & $2.77[1.26-6.11]$ & $2.57[1.14-5.79]$ & .023 \\
\hline Dyslipidemia & $129(34.8)$ & $36(31.3)$ & .493 & & & \\
\hline Metabolic Syndrome & $34(9.3)$ & $21(19.1)$ & .006 & $2.29[1.27-4.14]$ & $1.93[1.05-3.56]$ & .034 \\
\hline Number of major cardiovascular risk factors & $1[1-2]$ & $2[1-2]$ & .005 & 1.34 [1.09-1.65] & $1.14[0.90-1.43]$ & .267 \\
\hline 0 & $67(18.0)$ & $9(7.8)$ & & & & \\
\hline 1 & $134(35.9)$ & $45(39.1)$ & .02 & $2.5[1.15-5.42]$ & $1.49[0.66-3.40]$ & .338 \\
\hline 2 & $120(32.2)$ & $35(30.4)$ & .055 & $2.17[0.98-4.79]$ & $1.07[0.44-2.56]$ & .885 \\
\hline$\geq 3$ & $52(13.9)$ & $26(22.6)$ & .002 & $3.72[1.61-8.62]$ & $1.85[0.74-4.63]$ & .187 \\
\hline One or more non-accidental falls in the year & $29(7.9)$ & $12(10.5)$ & .376 & & & \\
\hline Risk of malnutrition/malnutrition (MNA $<12$ ) & $21(5.7)$ & $4(3.5)$ & .355 & & & \\
\hline
\end{tabular}


Unintentional weight loss $\geq 4.5 \mathrm{~kg}$ in the past year

\section{Mobility and muscle strength}

Gait speed m/s, median [IQR]

Slowness (gait speed $<1 \mathrm{~m} / \mathrm{s}$ )

Ten-meter walking test times during a concurrent task

$$
\text { Motor dual task, } \mathrm{s} \text { § }
$$

Cognitive dual task, $\mathrm{s}^{\S}$

Appendicular lean mass index, $\mathrm{kg} / \mathrm{m}^{2}<7.23$ (male) or 5.67 (female)

Weakness (grip), stratified by sex and body mass index

Time getting up from a chair (5 times) $>11.19 \mathrm{~s}$

Sarcopenia

\section{Balance}

One-leg standing test $<5 \mathrm{~s}$

Failure to resist a sternal push

\section{Bone mineral density)}

Normal (T-score > -1)

Osteopenia (T-score between -1 and -2.5 )

Osteoporosis $(\mathrm{T}$-score $<=-2.5$ )

Exhaustion **

Physical frailty phenotype (modified CHS criteria)

\section{Robust}

Pre-frail

Frail

Depressive symptoms (GDS score $\geq 11 / 30$ or $5 / 15$ ) ** Cognition \#

\begin{tabular}{|c|c|c|c|c|c|}
\hline $9(2.6)$ & $6(5.4)$ & .149 & 2.14 [0.74-6.15] & $2.13[0.71-6.38]$ & .175 \\
\hline $1.43[1.25-1.67]$ & 1.37 [1.18-1.54] & .011 & $0.40[0.19-0.85]$ & $0.54[0.26-1.15]$ & .109 \\
\hline $10(2.7)$ & $5(4.4)$ & .362 & & & \\
\hline $7[6-8]$ & 7.5 [6.7-8.6] & $<.001$ & $1.24[1.03-1.50]$ & $1.18[0.98-1.42]$ & .078 \\
\hline $7.3[6.5-8.5]$ & 8.2 [7-10] & $<.001$ & $1.33[1.10-1.60]$ & $1.27[1.05-1.53]$ & .012 \\
\hline $37(9.9)$ & $12(10.4)$ & .872 & & & \\
\hline $135(36.3)$ & $43(37.4)$ & .83 & & & \\
\hline $38(10.3)$ & $12(10.9)$ & .861 & & & \\
\hline $18(4.8)$ & $7(6.1)$ & .592 & & & \\
\hline $40(10.9)$ & $8(7.0)$ & .23 & & & \\
\hline $21(5.8)$ & $8(7.1)$ & $\begin{array}{l}.625 \\
.328\end{array}$ & & & \\
\hline $166(45.4)$ & $40(37.4)$ & & & & \\
\hline $144(39.3)$ & 47 (43.9) & & & & \\
\hline $56(15.3)$ & $20(18.7)$ & & & & \\
\hline 87 (29.9) & $22(28.2)$ & .77 & & & \\
\hline & & .483 & & & \\
\hline $98(26.4)$ & $27(24)$ & & & & \\
\hline $253(68.5)$ & 77 (68.8) & .732 & & & \\
\hline $19(5.1)$ & $8(7.1)$ & .381 & & & \\
\hline $42(12.9)$ & $23(23.2)$ & .013 & $1.92[1.10-3.35]$ & $1.86[1.04-3.32]$ & .037 \\
\hline
\end{tabular}


MMSE $\leq$ lower quartile, according to age and educational level

$\begin{array}{cccccc}40(11.1) & 22(21.0) & <.001 & 2.19[1.17-4.08] & 2.56[1.35-4.88] & \mathbf{. 0 0 4} \\ 5(1.3) & 6(5.2) & \mathbf{. 0 2 5} & 4.45[1.32-15.03] & 4.11[1.12-15.02] & \mathbf{. 0 3 3} \\ 50(13.4) & 31(27.0) & \mathbf{. 0 0 1} & 2.18[1.26-3.78] & 1.79[1.01-3.16] & \mathbf{. 0 4 6}\end{array}$

Frontal Assessment Battery score $<16$

$50(13.4)$

$31(27.0)$

.001

Scheltens score

0

$190(62.7)$

$40(40.4)$

1

2-3

$94(31.0) \quad 49(49.5)$

$19(6.3)$

$10(10.1)$

$<.001 \quad 2.20[1.37-3.53]$

$1.83[1.13-2.99]$

.015

Fazekas score

$242(85.2) \quad 71(82.6)$

$\begin{array}{lcc}0-1 & 242(85.2) & 71(82.6) \\ 2-3 & 42(14.8) & 15(17.4)\end{array}$

Variables are expressed as the $\mathrm{n}(\%)$, unless otherwise stated.

Abbreviations: IQR, interquartile range; MNA, Mini Nutritional Assessment; MMSE, Mini Mental State Examination; GDS, Geriatric Depression Scale; CHS, Cardiovascular Health Study; MRI, magnetic resonance imaging.

${ }^{*} \mathrm{P}$ value in a Mann-Whitney, $\mathrm{Chi}^{2}$ or Fisher test, as appropriate; logistic regression analyses were used to estimate ${ }^{\dagger}$ crude and $^{\ddagger}$ age-adjusted odds ratios, and ${ }^{\#}$ odds ratios adjusted for depressive symptoms and educational level; *** odds ratios estimated after multiple imputation (> 5\% missing values).

$\S$ Odds ratios and confidence intervals are given for one standard deviation of the log-transformed value.

"Regular physical activity, including walking, recreational sports and other physical activities.

${ }^{\dagger \dagger}$ Myocardial infarction was considered if occurred before 55 [men] or 65 (women) years of age.

\#‡ Personal history of cardiovascular disease includes: stroke, transient ischemic attack, and coronary heart disease.

${ }^{\S}$ Hypertension, defined as a systolic blood pressure $\geq 140 \mathrm{mmHg}$ or a diastolic blood pressure $\geq 90 \mathrm{mmHg}$ or ongoing treatment for hypertension.

III Major cardiovascular risk factors, including male sex, age > 60 years (female), hypertension, smoking (current or past 3 years), dyslipidemia, diabetes, and first degree relative(s) with sudden death, or myocardial infarction before 55 [men] or 65 (women) years of age. 
"The modified CHS criteria were unintentional weight loss $\geq 4.5 \mathrm{~kg}$ in the year, self-reported exhaustion, poor grip strength, gait speed $<1 \mathrm{~m} / \mathrm{s}$ and low physical activity ( $<7500$ steps/day and no regular physical activity). Individuals with $\geq 3$ criteria are considered to be frail, those with $1-2$ criteria are considered to be pre-frail, and those with no criteria are considered to be robust. 